This is the accepted version of the following article:

Khater M., de la Escosura-Muñiz A., Quesada-González D., Merkoçi A.. Electrochemical detection of plant virus using gold nanoparticle-modified electrodes. Analytica Chimica Acta, (2019). 1046. : 123 - . 10.1016/j.aca.2018.09.031,

which has been published in final form at https://dx.doi.org/10.1016/j.aca.2018.09.031 () https://dx.doi.org/10.1016/j.aca.2018.09.031. This manuscript version is made available under the CC-BY-NC-ND 4.0 license http://creativecommons.org/licenses/by-nc-nd/4.0/ 


\title{
Electrochemical detection of plant virus using gold nanoparticle- modified electrodes
}

Mohga Khater ${ }^{1,2}$, Alfredo de la Escosura-Muñiz', Daniel Quesada-González'

\begin{abstract}
Arben Merkoçi ${ }^{1,3 *}$
${ }^{1}$ Catalan Institute of Nanoscience and Nanotechnology (ICN2), CSIC and Barcelona Institute of Science and Technology, Campus UAB, 08193 Barcelona, Spain.

${ }^{2}$ On leave from Agricultural Research Center (ARC), Ministry of Agriculture and land reclamation, Giza, Egypt

${ }^{3}$ ICREA—Institucio Catalana de Recerca i Estudis Avançats, Pg. Lluís Companys 23, 08010 Barcelona, Spain.
\end{abstract}

Phone number: +34937374604 ; Fax number: +34935868020

*E-mail: arben.merkoci@icn2.cat 


\section{ABSTRACT}

Tristeza is one of the destructive diseases of citrus causing by citrus tristeza virus (CTV). Historically, CTV has been associated with serious outbreaks of quick decline of citrus, therefore CTV monitoring is important aspect for avoiding such re-emerging epidemics, which would threat citrus production through the world. In this context, we have designed for the first time a label-free impedimetric biosensor for the detection of nucleic acid of CTV. The sensing platform based on a screen-printed carbon electrode (SPCE) was modified by electrodeposited gold nanoparticles (AuNPs), which allowed to efficiently immobilizing thiolated ssDNA probes as well to enhance the electrode conductivity. The growth of AuNPs was optimized and characterized using scanning electron microscopy (SEM), cyclic voltammetry $(\mathrm{CV})$ and electrochemical impedance spectroscopy (EIS). We investigated the behavior of thiolated ssDNA probe layer and its hybridization with target DNA onto AuNP surfaces by EIS measurements in $\mathrm{Fe}\left(\mathrm{CN}_{6}\right)^{4-} / \mathrm{Fe}\left(\mathrm{CN}_{6}\right)^{3-}$ red-ox system. The main sensor design aspects such as AuNPs size, probe DNA concentration and immobilization time together with DNA hybridization time were optimized so as to achieve the best performance. Impedance values of DNA hybridization increased with Citrus tristeza-related synthetic DNA concentration, showing a logarithmic relation in the range of 0.1 to $10 \mu \mathrm{M}$. The results also indicate that the biosensor was able to selectively detect CTV nucleic acids in the presence of other non-specific DNAs. Moreover, we have demonstrated the good performance of the system in a real plant sample matrix. In addition, the sensor reproducibility enhanced after the hybridization onto $\mathrm{MCH} /$ poly (AT) thiolated DNA probes which was confirmed by intra- and inter- day variability assays.

\section{KEYWORDS}

Electrochemical impedance spectroscopy, DNA, Gold-nanoparticles, Virus, Plant pathogen, citrus tristeza virus 


\section{INTRODUCTION}

Plant diseases have great impact on global plant production threating world food security (Roberts et al., 2006; Savary et al., 2012). Their causal agents include nonpathogenic factors such as environment, mechanical and chemical or pathogenic agents mainly viruses, fungi, bacteria and nematodes, etc. The most frequent methods for plant disease detection are based on nucleic acid and protein analysis. Over the past two decades, major advances in nanotechnology have allowed plant pathologists to integrate new technologies with molecular biology for plant disease diagnosis. In recent years, several reviews on developing biosensing systems for plant disease detection were reported (Nezhad, 2014; Fang and Ramasamy, 2015; Martinelli et al., 2015; Khater et al., 2017). Among major citrus viruses, Citrus tristeza virus (CTV) has caused high plant death rates around the world especially where citrus seedlings grafted onto sour orange rootstocks (the most susceptible to sever strains of tristeza) are cultivated (Moreno et al., 2008; Harper and Cowell, 2016). Tristeza infects the phloem cells then systematically invades the tree causing variable symptoms that may include small fruit with low quality, general yellowing, step-pitting and quick decline (Bar-Joseph et al., 1989; Licciardello et al., 2015; Bar-Joseph, 2015). The CTV-infected plants may display symptoms ranging from mild to severe depending mostly on the virus variant and susceptibility of plant variety. According to European and Mediterranean Plant Protection Organization (EPPO), CTV is a quarantine pathogen. Most reported serological assays to identify the coat protein of CTV are mainly ELISA, direct tissue print immunoassays (Bar-Joseph et al., 1978; Huang et $a l ., 2004)$ and very recently lateral flow immunoassay and label-free electrochemical immunosensor were developed for CTV detection (Haji-Hashemi et al., 2017; Maheshwari et al., 2017). Since reverse transcription polymerase chain reaction (RT-PCR) and dot- blot hybridization based methods are the most commonly used in molecular diagnostics of CTV, a combination of reverse transcription with loop-mediated isothermal amplification technology (RT-LAMP) has been recently developed (Korkmaz et al., 2008; Yakomi et al., 2010; 
Warghane et al., 2017). However, these methodologies are time-consuming, requiring specialized personnel and also have limitations related to primer design. Applications of electrochemical nucleic acid sensing in disease diagnostics are growing tremendously over the last decades. Electrical detection of DNA hybridization using sensors has offered great sensitivity, cost-effective and easy rapid DNA analysis avoiding the limits of classical DNA hybridization detection techniques such as membrane blots and gel electrophoresis. To date, several studies have reviewed electrochemical nucleic acid biosensors based on different electrochemical approaches and have discussed the recent strategies for DNA immobilization and hybridization detection techniques (Wang, 2002; Merkoçi et al., 2005; Castañeda et al., 2007 and 2009; Park et al., 2009; Abdul Rashid and Yusof, 2017). Earlier publications addressed detection of nucleic acid of infectious agents using voltammetric, amperometric and impedance electrochemical approaches (Hassen et al., 2008; Pournaghu-Azar et al., 2008; Cash et al., 2009; Benvidi et al., 2015). Notably, DNA hybridization biosensors based on electrochemical spectroscopy impedance (EIS) are being developed in both label-free formats and label-based approaches using mostly gold nanoparticle (AuNP) and cadmium sulfide quantum dot (CdS QD) as tags (Wang et al., 2002 and 2003; Xu et al., 2004; Pumera et al., 2005; Bonanni et al., 2008; Rasheed and Sandhyarani, 2017 ; Ribovski et al., 2017) also employing other nanomaterials (Wang et al., 2003; De la Escosura-Muñiz and Merkoçi, 2010; Merkoçi, 2010; De la Escosura-Muñiz and Merkoçi, 2014; Mayorga-Martinez et al., 2015; De la Escosura-Muñiz et al., 2016). Modification of electrode surface for immobilization of biorecognition receptor (i.e. DNA probes, antibody, aptamer, etc.) is the key to successful monitoring of DNA hybridization event. Most of such impedimetric DNA sensors have been designed forming self-assembled monolayers (SAM) on gold electrodes and films of conducting polymers (i.e. pyrrole) and nanomaterials, especially AuNPs, as electrode modifiers (Travas-Sejic et al., 2005; Ito et al., 2007; Li et al., 2008). Introducing AuNPs into electrochemical DNA sensing electrodes offers several advantages over other metal 
nanoparticles and oxides. Unlike graphene and iron oxides, the strong stable gold ( $\mathrm{Au})$-sulfur (S) bond together with their unique properties such as large surface and high conductivity, providing efficient immobilization of bio-receptor probes have made AuNPs as the most popular nanomaterial, extensively exploited in the design of biosensors. (Deng et al., 2009; Mazloum-Ardakani et al., 2013; Zhang et al., 2015). Label-free sensors using impedimetric detection and label-based voltammetric approaches using enzymes or methylene blue tags on gold and carbon electrodes have been extensively reported (Liu et al., 2005; Zhang et al., 2008; Lai and Weiwei, 2011, Peng et al., 2015; Cui et al., 2017).

Due to significant improvement in biosensor technology over the last two decades, applications of screen-printed electrodes (SPEs) in electrochemical DNA hybridization biosensors are in increase because of their simplicity, portability and the use of economical substrates. Moreover these SPEs offer the possibility of small-volume bioassays and can be combined with electrodeposited nanoparticles, especially AuNPs (Bonanni et al., 2010; Wu et al., 2013; Voccia et al., 2016; Arduini et al., 2016).

In this context, we propose for the first time to combine the advantages of AuNP-modified electrodes and EIS-based DNA hybridization detection for the development of a biosensor for CTV-related DNA determination. Such biosensor would be of high potential interest for infield applications in the relevant field of plant pathogen detection. 


\section{EXPERIMENTAL SECTION}

\subsection{Chemicals and equipment}

Gold (III) chloride hydrate $\left(\mathrm{HAuCl}_{4}, 99.9 \%\right)$, potassium hexacyanoferrate (III), potassium hexacyanoferrate (II), tris (2-carboxyethyl) phosphine (TCEP), $\mathrm{NaCl}, \mathrm{MgCl}_{2}, \mathrm{CaCl}_{2}, 6$ Mercaptohexanol $(\mathrm{MCH})$ and phosphate buffered saline were obtained from Sigma Aldrich (Spain). CTV immunostrips were provided by Agdia inc. (USA). Oligonucleotides were purchased from Isogen (Spain). Sequences are the following: Thiolated ssDNA probe: $5^{6}-$ GGATCGATGTGTAA-3'-( $\left.\mathrm{CH}_{2}\right)_{6}-\mathrm{HS}$; Target ssDNA (fully complementary; characteristic of CTV): 5'-TTACACATCGATCC -3'; partially non complementary ssDNA (characteristic of Psorosis virus): 5'-TTACACAAGGATCT-3'; fully non complementary ssDNA 5'TAGGATTAGCCGCATTCAGG-3' as control sequences. Thiolated ssDNA probe was pretreated as detailed at the supplementary information. All buffer solutions were prepared with ultrapure water of Milli-Q water purification system (with resistivity of $18.2 \mathrm{M} \Omega \mathrm{cm}$ ). The supporting electrolyte was $0.5 \mathrm{mM}$ solution of $\mathrm{K}_{3}\left[\mathrm{Fe}(\mathrm{CN})_{6}\right] / \mathrm{K}_{4}\left[\mathrm{Fe}(\mathrm{CN})_{6}\right]$ in $0.1 \mathrm{M} \mathrm{KCl}$. DNA probe and target sequences were diluted in $34 \mathrm{mM}$ Tris- $\mathrm{HCl}, \mathrm{pH} 7.4$ buffer. The washing solution was $0.01 \mathrm{M}$ phosphate buffered saline (PBS; $\mathrm{pH}$ 7.4). Stock solutions of the oligonucleotides were prepared in TE (0.01 M Tris-HCl; pH 8.2 and 0.001 M EDTA) buffer solution and kept frozen at $-20{ }^{\circ} \mathrm{C}$. Healthy citrus leaves were provided by Universitat Autònoma de Barcelona in Spain and for detailed preparation of leaf extracts and its screening for CTV, see the supplementary information. SEM images of the modified carbon working electrode with electrodeposited gold nanoparticles were obtained using a FEI Quanta ${ }^{\mathrm{TM}} 650$ field emission gun scanning electron microscope (FEI, USA). Images were analyzed using Image $\mathbf{J}$ software (National Institutes of Health, USA) for measuring particles size and density. All electrochemical measurements were recorded using Autolab potentiosat PGSO0 supported by two different softwares: FRA for impedance spectra analysis and GPES for 
voltammetric analysis. Home-made screen-printed carbon electrodes (SPCEs) preparation is detailed at the supplementary information.

\subsection{Methods}

\subsubsection{AuNPs electrodeposition}

Two-step electrochemical pre-treatment was applied on SPCEs under a potential of $+1.6 \mathrm{~V}$ for $120 \mathrm{~s}$ and of $+1.8 \mathrm{~V}$ for $60 \mathrm{~s}$ in acidic solution ( $0.1 \mathrm{M}$ acetate buffer; $\mathrm{pH} 4.7)$. Major advantages of this pretreatment included cleaned carbon surface from possible printing contaminants, higher hydrophilicity and better electron transfer at the working electrode surface (Pereira et al., 2011). Importantly, the working $\mathrm{pH}$ of 1-3 for gold solution to perform deposition was found to be significantly favorable for controlling particle size and distribution over carbon electrodes (Karoonian et al., 2012). The deposition process of AuNPs on SPCEs was performed by immersion into a gold solution of $\mathrm{pH} 1\left(0.01 \% \mathrm{HAuCl}_{4}, / 0.1 \mathrm{M} \mathrm{NaCl}\right.$ in the presence of $1.5 \mathrm{wt} \% \mathrm{HCl}$ ). Reduction of chloride gold (III) complexes to gold (0) and further deposition were achieved by applying a constant negative potential of $-0.4 \mathrm{~V}$ for a determined time (from $10 \mathrm{~s}$ to $1200 \mathrm{~s}$ ). Then the modified SPCEs were carefully rinsed and dried with nitrogen gas. After deposition of AuNPs onto carbon working electrode, AuNPSPCE was characterized using CV, EIS and SEM.

\subsubsection{Probe ssDNA immobilization and hybridization with target ssDNA}

The covalent attachment of thiolated ssDNA probes onto the deposited AuNPs of the pretreated electrodes was performed by incubation of $15 \mu \mathrm{L}$ of thiolated ssDNA probes solution at room temperature for $2 \mathrm{~h}$. After that, the electrodes were rinsed with PBS and 
Milli-Q water (3X). The concentration and incubation time of thiolated ssDNA probe were optimized as shown at section 3.2.

Hybridization with complementary target ssDNA was performed by adding $15 \mu \mathrm{L}$ and incubating during $60 \mathrm{~min}$ at room temperature. The same procedure was followed for the control assays with the non-complementary strand. A scheme of the developed DNA biosensing platform is shown at Figure 1.

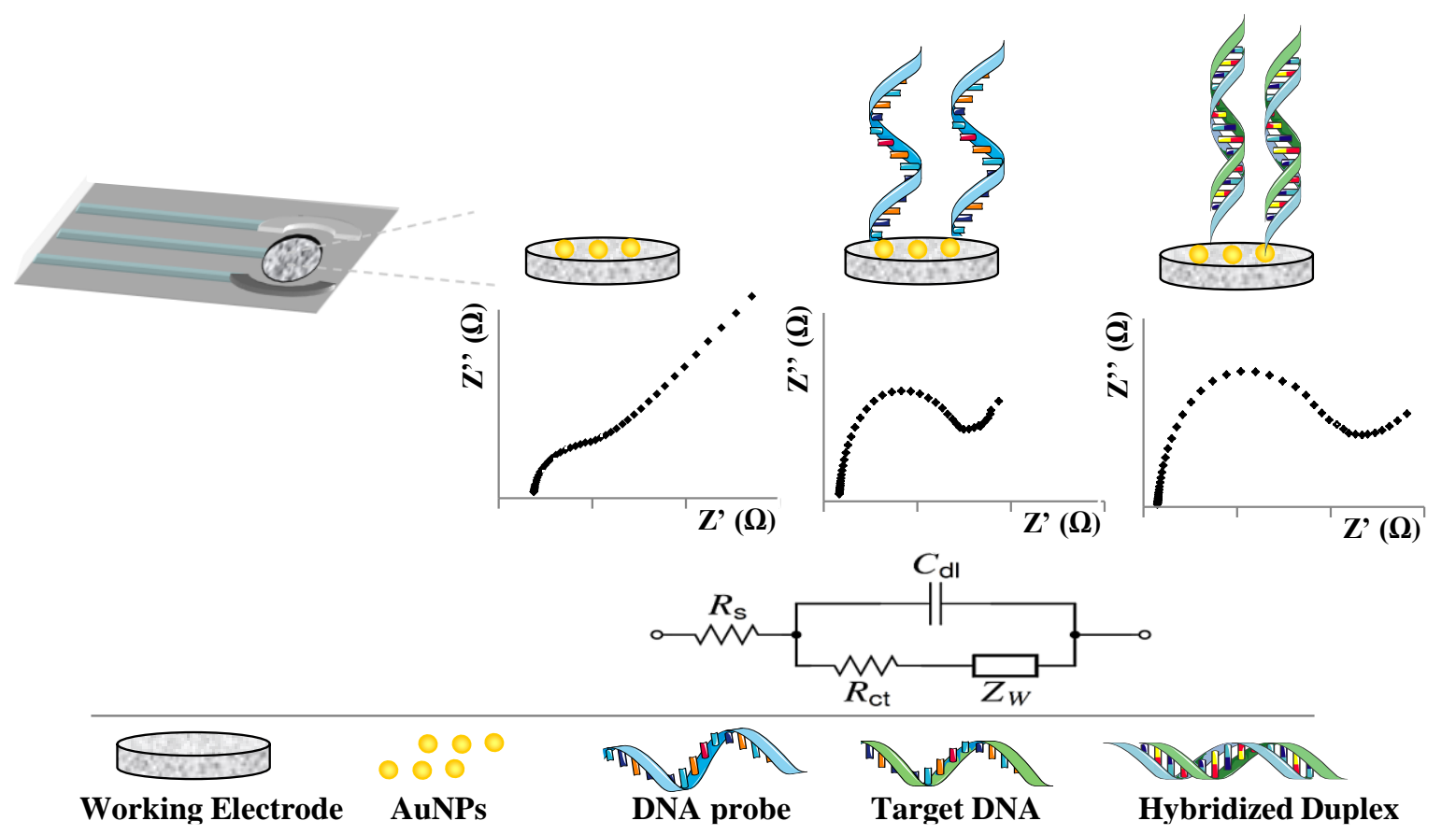

Figure 1. Scheme of the developed DNA hybridization sensor based on AuNP- modified SPCE employing label-free impedance for the detection of CTV-related nucleic acid. Graphs illustrate the trend of the Nyquist plots for the stepwise of the biosensor. The equivalent circuit consists of four main parameters: solution resistance (Rs), Warburg impedance (Zw), double layer capacity $(\mathrm{Cdl})$ and $\mathrm{R}_{\mathrm{ct}}$ for charge transfer resistance between the modified electrode and red-ox system. All EIS measurements were based on $R_{\mathrm{ct}}$ values. 


\subsubsection{Electrochemical measurements}

$\mathrm{CV}$ and EIS were used for the characterization of the AuNP-modified SPCEs, while the stepwise of the biosensor was characterized by EIS technique.

CVs were carried out in $0.5 \mathrm{M} \mathrm{H}_{2} \mathrm{SO}_{4}$ and $0.5 \mathrm{mM} \mathrm{K}_{3}\left[\mathrm{Fe}(\mathrm{CN})_{6}\right] / \mathrm{K}_{4}\left[\mathrm{Fe}(\mathrm{CN})_{6}\right]$ in $0.1 \mathrm{M} \mathrm{KCl}$ from +1.4 to $-0.6 \mathrm{~V}$ at a scan rate of $50 \mathrm{mV} / \mathrm{s}$. EIS measurements were performed in $0.5 \mathrm{mM}$ $\mathrm{K}_{3}\left[\mathrm{Fe}(\mathrm{CN})_{6}\right] / \mathrm{K}_{4}\left[\mathrm{Fe}(\mathrm{CN})_{6}\right]$ in $0.1 \mathrm{M} \mathrm{KCl}$ within frequency ranging from $10 \mathrm{KHz}$ to $0.5 \mathrm{~Hz}$ and alternating voltage amplitude of $5 \mathrm{mV}$. The results of impedance measurements were represented in the form of the Nyquist plot which visually shows the system dynamics.

The diameter of semicircle in the Nyquist plot is assigned to $\mathrm{Fe}\left[(\mathrm{CN})_{6}\right]^{4-3-}$-charge transfer resistance (Rct) at high frequency when a line portion yielded from mass transfer limitation process at low frequencies. The difference in charge transfer resistance before and after DNA hybridization and duplex DNA (dsDNA) formation $\left(\Delta \mathrm{R}_{\mathrm{ct}}\right)$ were obtained following equation $\Delta \mathrm{R}_{\mathrm{ct}}=\left(\mathrm{R}-\mathrm{R}_{0}\right) / \mathrm{R}_{0}$. Here $\mathrm{R}$ and $\mathrm{R}_{0}$ are charge transfer resistance of dsDNA and ssDNA, respectively. For analytical analysis, $\mathrm{R}_{\mathrm{ct}}$ was measured by fitting data to equivalent circuits (Randless circuit) using the tools of the FRA software. Mean and standard deviation for all EIS reported results were calculated to represent obtained data. EIS and CV tests were conducted under ambient conditions.

\section{RESULTS AND DISCUSSION}

\subsection{Characterization of AuNP-modified SPCEs}

Gold deposition time was evaluated so as to obtain the optimum size and distribution of the AuNPs on the carbon working electrode for improving the analytical performance of our DNA hybridization biosensor. A constant negative potential of $-0.4 \mathrm{~V}$ was applied for different deposition times (ranging from $10 \mathrm{~s}$ to $1600 \mathrm{~s}$ ) and the obtained surface was 
monitored using SEM and EIS. As shown in Figure 2, SEM images of the carbon working area of the SPCEs before and after gold electrodeposition at different times allow to verify AuNPs formation and to evaluate the particle size, morphology and density. A low amount (approx. 20 particles $/ \mu \mathrm{m}^{2}$ ) of small AuNPs (approx. $25 \mathrm{~nm}$ ) with sharp tips was observed for short electrodeposition times in the range from 10-25 seconds. AuNPs nucleation increases then with the time, reaching saturation (approx. 50 particles $/ \mu \mathrm{m}^{2}$ ) for 200 seconds. An increase in the AuNPs size was observed for longer times, being larger than $85 \mathrm{~nm}$ for 1200 seconds. AuNPs aggregation was observed for electrodeposition times longer than 1200 seconds (data not shown). In view of these results, a compromise between AuNPs size, density, dispersity and experimental time is estimated for 200 seconds of electrodeposition, being such conditions selected as optimum for the further development of the DNA biosensor (as was also corroborated by the EIS characterization - see section 3.2).

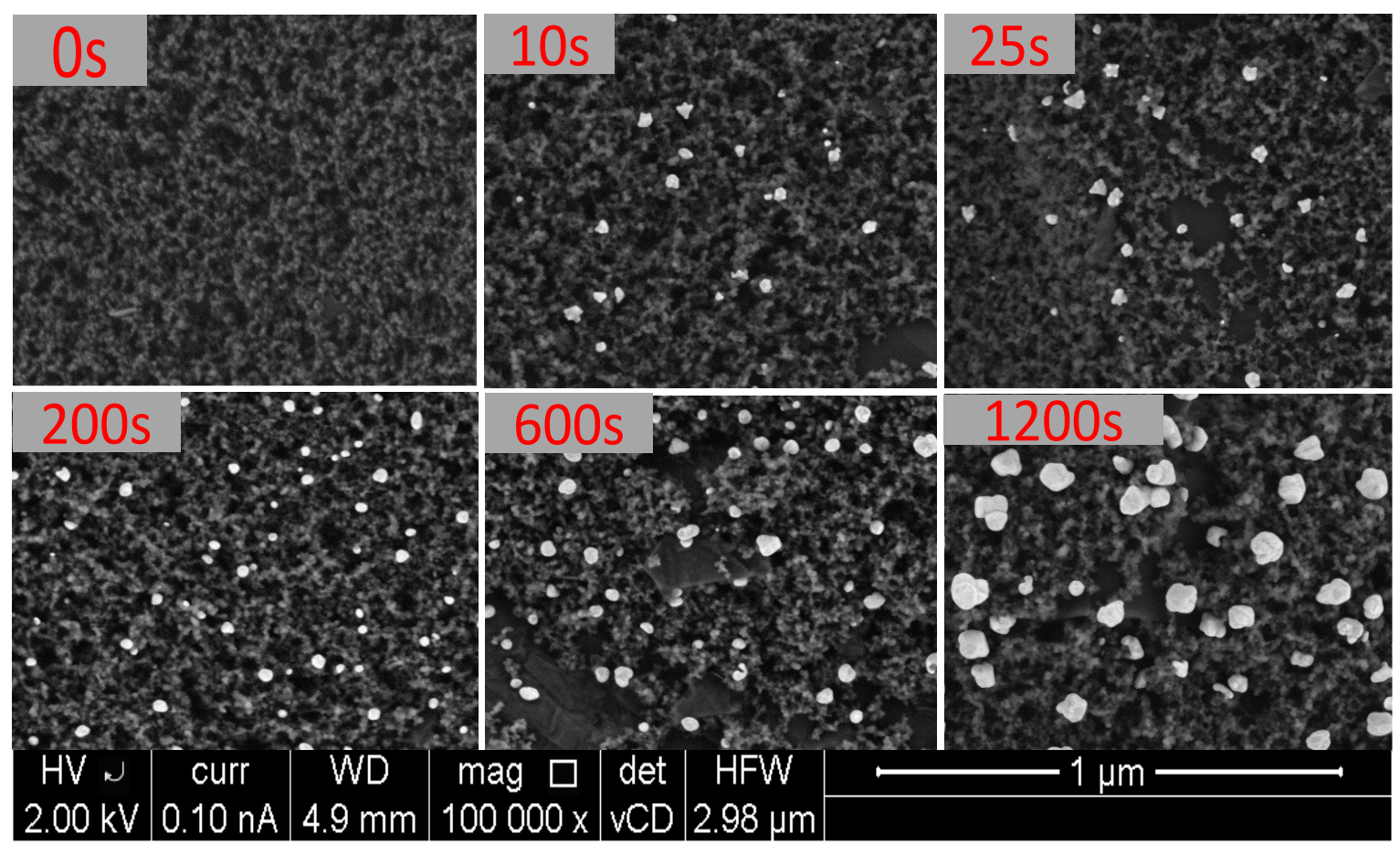

Figure 2. SEM images of the carbon working area of SPCEs after different gold electrodeposition times (from 0 to 1200 seconds). Precursor: $0.01 \% \mathrm{HAuCl}_{4}$ solution. Deposition potential: $-0.4 \mathrm{~V}$. 
The presence of AuNPs in the as-modified electrode (200 seconds of electrodeposition) was also evaluated by $\mathrm{CV}$ in $0.5 \mathrm{M} \mathrm{H}_{2} \mathrm{SO}_{4}$ solution (Figure $3 \mathrm{~A}$ ). An anodic current peak at around $+0.9 \mathrm{~V}$ and a cathodic counterpart at around $+0.5 \mathrm{~V}$ were observed for the AuNP-modified electrodes (Figure 3A-solid line), which reflect the oxidation of AuNPs and the subsequent reduction of the gold oxide species back to metallic gold, respectively. In contrast, there was no appearance of any distinct faradaic current peak for bare SPCE (Figure 3A-dotted line).

The effect of the AuNPs on the electrode electron transfer was also evaluated by CV in 0.5 $\mathrm{mM} \quad \mathrm{K}_{3}\left[\mathrm{Fe}(\mathrm{CN})_{6}\right] / \mathrm{K}_{4}\left[\mathrm{Fe}(\mathrm{CN})_{6}\right]$ (Figure 3B). A pair of well-defined red-ox peaks corresponding to oxidation/reduction of the pair $\mathrm{Fe}\left[(\mathrm{CN})_{6}\right]^{3-/} \mathrm{Fe}\left[(\mathrm{CN})_{6}\right]^{4-}$ at $+0.36 \mathrm{~V} /+0.12 \mathrm{~V}$ were observed for both the bare (Figure 3B-dotted line) and AuNP-modified SPCE (Figure 3B-solid line). The increase in the electron transfer on the electrode thanks to the presence of the AuNPs is evident when comparing the peak current intensities, observing an increase of $28 \%$ in the current for the modified SPCE.

Impedimetric investigation in $0.5 \mathrm{M} \mathrm{K}_{3}\left[\mathrm{Fe}(\mathrm{CN})_{6}\right] / \mathrm{K}_{4}\left[\mathrm{Fe}(\mathrm{CN})_{6}\right]$ solution also evidences the modification of SPCEs with AuNPs. A well-defined semicircle along Z' with diameter corresponding to Rct resistance was obtained for both bare (Figure 3C-dotted line) and AuNP-modified SPCE (Figure 3C-solid line). The lower impedance recorded for the modified electrode (185\% decrease in the Rct) evidences the improved electrical conductivity raised by the presence of AuNPs. 


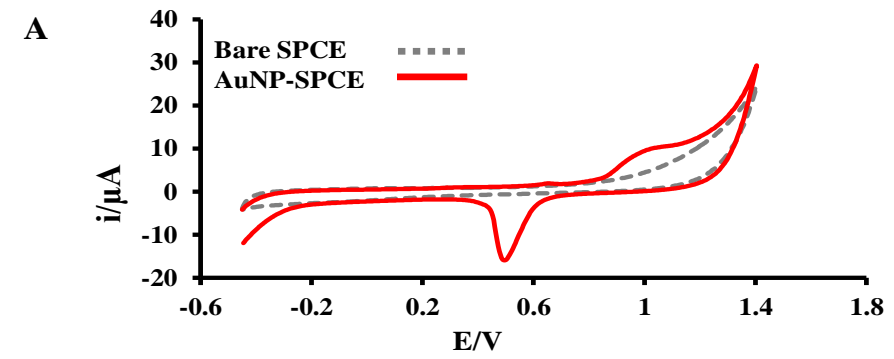

B
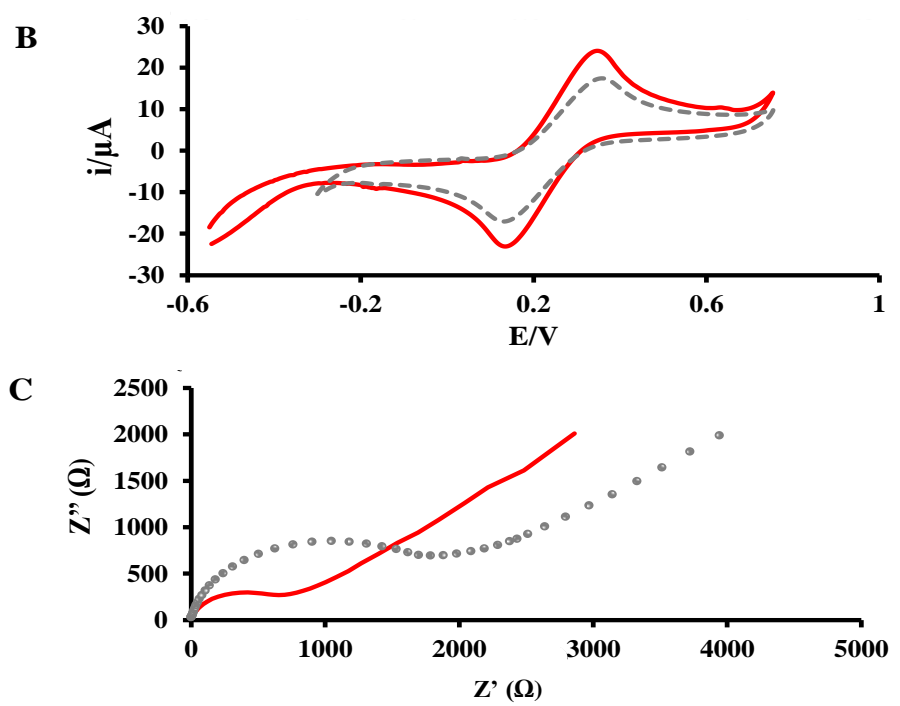

Figure 3. Cyclic voltammograms (CVs) and Nyquist plots recorded for bare SPCEs (dotted lines) and AuNP-modified SPCEs after 200s of gold deposition (solid lines). A. CVs in $0.5 \mathrm{M}$ $\mathrm{H}_{2} \mathrm{SO}_{4}$; B. CVs in $0.5 \mathrm{mM} \mathrm{K}_{3}\left[\mathrm{Fe}(\mathrm{CN})_{6}\right] / \mathrm{K}_{4}\left[\mathrm{Fe}(\mathrm{CN})_{6}\right]$ containing $0.1 \mathrm{M} \mathrm{KCl}$. C. Nyquist plot obtained in $0.5 \mathrm{mM} \mathrm{K}_{3}\left[\mathrm{Fe}(\mathrm{CN})_{6}\right] / \mathrm{K}_{4}\left[\mathrm{Fe}(\mathrm{CN})_{6}\right]$ containing $0.1 \mathrm{M} \mathrm{KCl}$. CVs are recorded from +1.4 to $-0.6 \mathrm{~V}$ at scan rate of $50 \mathrm{mV} / \mathrm{s}$. Nyquist plots recorded by applying potential of $+0.2 \mathrm{~V}$ under amplitude of $5 \mathrm{mV}$ in a frequency range of $10 \mathrm{KHz}$ to $0.5 \mathrm{~Hz}$. 


\subsection{DNA hybridization biosensor optimization}

The main parameters affecting the performance of the DNA hybridization biosensor (performed following the experimental procedure described at section 2.2, fixing a target ssDNA concentration of $1 \mu \mathrm{M}$ ) were evaluated by EIS. Nyquist plots were recorded in 0.5 $\mathrm{mM} \mathrm{K} \mathrm{K}_{3}\left[\mathrm{Fe}(\mathrm{CN})_{6}\right] / \mathrm{K}_{4}\left[\mathrm{Fe}(\mathrm{CN})_{6}\right]$ containing $0.1 \mathrm{M} \mathrm{KCl}$ solution and the signals were normalized by following the equation described at section 2.3 .

Since deposition time tunes particle size and shape, the effect of the gold electrodeposition time and optimum particle size for high DNA hybridization rate was first evaluated (Figure 4A). Preceding this, we have studied the behavior of thiolated ssDNA probes on varying diameter of AuNPs. The immobilized thiolated ssDNA had the highest signal value onto AuNPs with average diameter of $25 \mathrm{~nm}$ (obtained over $25 \mathrm{~s}$ ) and then the charge transfer resistance decreased with the increasing of particle size. In contrast, the hybridization with target ssDNA using $25 \mathrm{~nm}$ AuNPs had the lowest $\Delta$ Rct signal value. This is probably because small AuNPs completely packed with the thiolated DNA probe, not allowing sufficient space for target DNA to hybridize (data not shown). Therefore, the optimum size of AuNPs corresponding to thiolated probe does not accurately reflect the needed thiolated probe density in DNA hybridization assays. Notably, while gold electrodeposition time increases (from $10 \mathrm{~s}$ - $200 \mathrm{~s}$ ), $\Delta$ Rct values of DNA hybridization increased reaching the highest for $200 \mathrm{~s}$ (average diameter of $50 \mathrm{~nm})$. Longer deposition times (600 s - $800 \mathrm{~s}$ ) showed a decrease in the $\Delta \mathrm{Rct}$ values and poor reproducibility, which is in line with what was observed by SEM analysis. From SEM images homogenous AuNPs with controlled shape and size were generated at 200 s while non-homogenous bigger gold particles were observed at $600 \mathrm{~s}$ (particles diameter data at supplementary information) and this may lead to irreproducibility of the DNA sensor. Overall, particles with an average diameter of $50 \mathrm{~nm}$ afforded the best DNA hybridization rate, thus $200 \mathrm{~s}$ was then selected as the optimum gold electrodeposition time. 


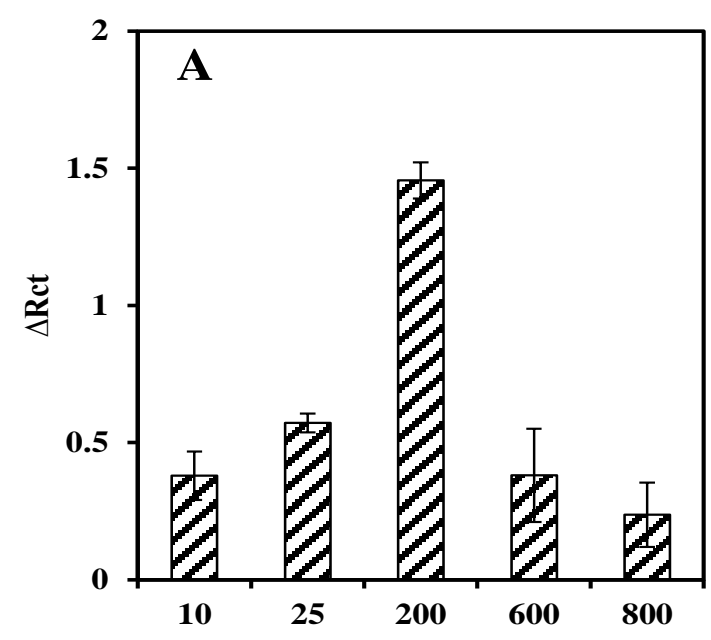

Au-deposition Time (seconds)

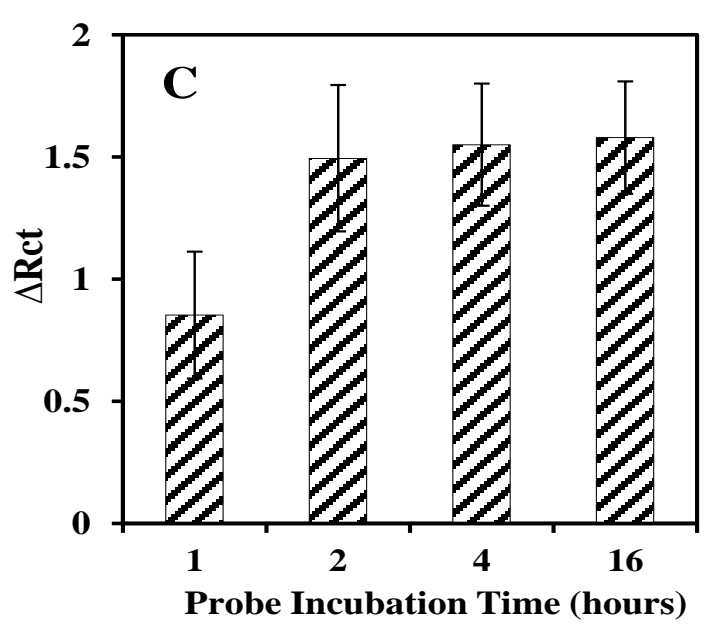

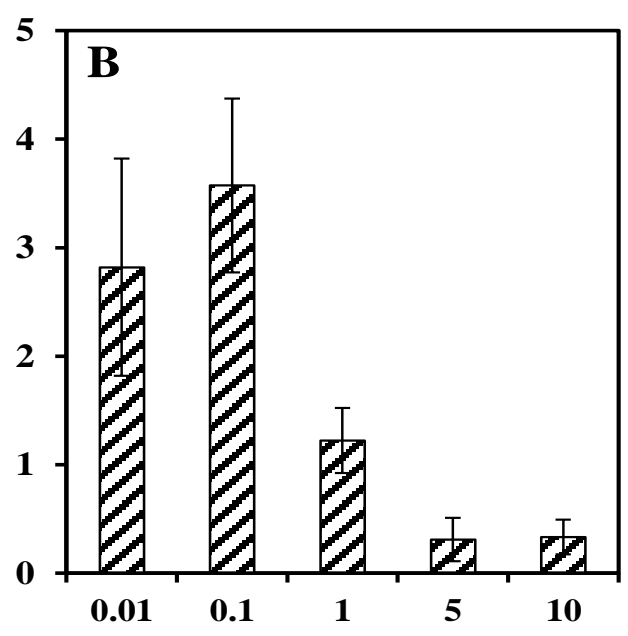

Probe Concentration $(\mu \mathrm{M})$

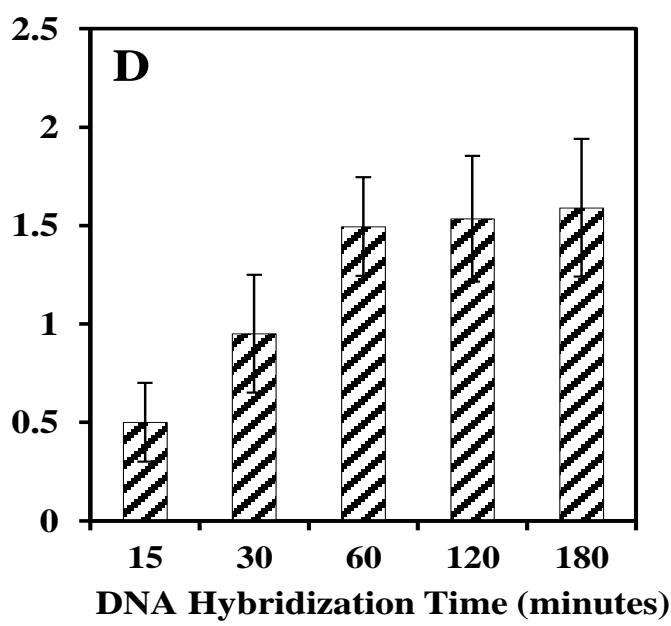

Figure 4. Optimization of DNA hybridization biosensor. Normalized values corresponding to $\Delta \mathrm{R}_{\mathrm{ct}}=\left(\mathrm{R}-\mathrm{R}_{0}\right) / \mathrm{R}_{0}$ are represented. $\Delta \mathrm{R}_{\mathrm{ct}}$ values were recorded after DNA hybridization with CTV-related DNA and control DNA $(1 \mu \mathrm{M})$ following A) AuNPs deposition times (ranging $10 \mathrm{~s}-800 \mathrm{~s})$ at potential of $-0.4 \mathrm{~V}$; thiolated ssDNA probe $(1 \mu \mathrm{M})$ incubated for $2 \mathrm{~h}$; DNA hybridization time: $1 \mathrm{~h} \mathrm{~B})$ Different probe ssDNA concentrations $(0.01,0.1,1,5$, and 10) $\mu \mathrm{M}$ on AuNP- modified SPCE (200 s); probe incubation time: $2 \mathrm{~h}$; DNA hybridization time: $1 \mathrm{~h}$ C) Probe incubation times $(1,2,4$ and $16 \mathrm{~h})$ of thiolated ssDNA probe $(0.1 \mu \mathrm{M})$ using AuNPmodified SPCE (200 s); DNA hybridization time: 1 h. D) DNA hybridization times (15, 30, 60,120 and $180 \mathrm{~min}$ ) on AuNP- modified SPCE (200 s) incubated with $0.1 \mu \mathrm{M}$ of thiolated ssDNA probe for $2 \mathrm{~h}$. 
Thiolated ssDNA probe concentration and immobilization time were also investigated. AuNP-modified electrodes were incubated with a wide range of thiolated probe ssDNA concentrations $(0.01,0.1,1,5$ and $10 \mu \mathrm{M})$. A gradual increase in the values of $\Delta$ Rct was observed for the smaller concentrations, observing a decrease for values higher than $0.1 \mu \mathrm{M}$ (Figure 4B). This suggests that high probe ssDNA concentrations saturate the surface of AuNPs, hindering the signal discrimination after hybridization. In view of these results, a ssDNA probe concentration of $0.1 \mu \mathrm{M}$ was selected for further studies.

Other parameter affecting the formation of the immobilized ssDNA probe sensing layer is the DNA probe incubation time, which was found to influence the DNA hybridization kinetics. The AuNP-modified SPCE electrodes were exposed to a $0.1 \mu \mathrm{M}$ of thiolated ssDNA probe for various times (1, 2, 4 and $16 \mathrm{~h}$ ) and EIS measurements after DNA hybridization were recorded (Figure $4 \mathrm{C}$ ). The $\Delta \mathrm{Rct}$ steadily increased for short times. After $2 \mathrm{~h}$ of probe ssDNA incubation and later hybridization with target ssDNA enlarged the diameter of semicircle to evidence the presence of sufficient attached ssDNA probe to recognize the target DNA and produce high analytical signal after hybridization. The $\Delta$ Rct values increased with the increasing in DNA probe incubation time under water-saturated atmosphere at $4^{\circ} \mathrm{C}$, demonstrating data saturation up to $16 \mathrm{~h}$. The electrochemical data indicated that the incubation period of $2 \mathrm{~h}$ was optimum for our biosensing system.

Finally, the effect of DNA hybridization time on the analytical signal was studied (Figure 4D). While membrane blot techniques require up to 16 hours or longer for base pairing interaction, DNA hybridization on small electrode surface modified with adequate probe ssDNA concentration using micro volume of solutions typically require $1-2 \mathrm{~h}$ for hybridization to occur. The AuNP- modified SPCE electrodes coated with thiolated ssDNA probe were incubated with target ssDNA for various times $(15,30,60,120$ and $180 \mathrm{~min})$ to lead to duplex DNA formation. A steady increase in the $\Delta$ Rct was observed over DNA 
hybridization times up to $60 \mathrm{~min}$, noticing saturation in the signal for longer times. DNA hybridization time of $1 \mathrm{~h}$ was consequently chosen for the next investigation.

\subsection{Citrus tristeza-related nucleic acid detection}

Citrus tristeza virus has many characterized strains causing different symptomology. A 14mer target ssDNA with sequence 5'-TTACACATCGATCC-3' was selected as characteristic of the major coat protein (P25) of CTV (Niblett, 2000). The optimized DNA sensor was tested for different target ssDNA concentrations under the optimized conditions (AuNPs deposition time: $200 \mathrm{~s}$, Probe concentration: $0.1 \mu \mathrm{M}$, probe incubation time: $2 \mathrm{~h}$ and DNA hybridization time: $1 \mathrm{~h}$ ). In the EIS Nyquist plot, the diameter of semicircle enlarged when target ssDNA concentration increased as shown at Figure 5A. Control assays performed with a non-specific target strand characteristic of Psorosis, another citrus virus genome (5'TTACACAAGGATCT-3') (Figure 5A-a) demonstrated our sensing system ability to differentiate between CTV-related and non-CTV-related DNA.

The normalized $R_{\mathrm{ct}}$ values vs the CTV-related DNA concentrations were plotted (Figure 5B), finding a logarithmic relationship in the range of 0.1 to $10 \mu \mathrm{M}$, adjusted to the following equation:

$$
\Delta \operatorname{Rct}(\Omega)=1.4199 \ln [\mathrm{CTV}(\mu \mathrm{M})]+5.83(\mathrm{r}=0.99) \quad\left(\Delta \mathrm{R}_{\mathrm{ct}}=\left(\mathrm{R}-\mathrm{R}_{0}\right) / \mathrm{R}_{0}\right)
$$

A limit of detection (LOD) of $100 \mathrm{nM}$ was estimated, as the target concentration giving a signal equal to the blank signal plus three times its standard deviation. 
$\mathbf{A}$

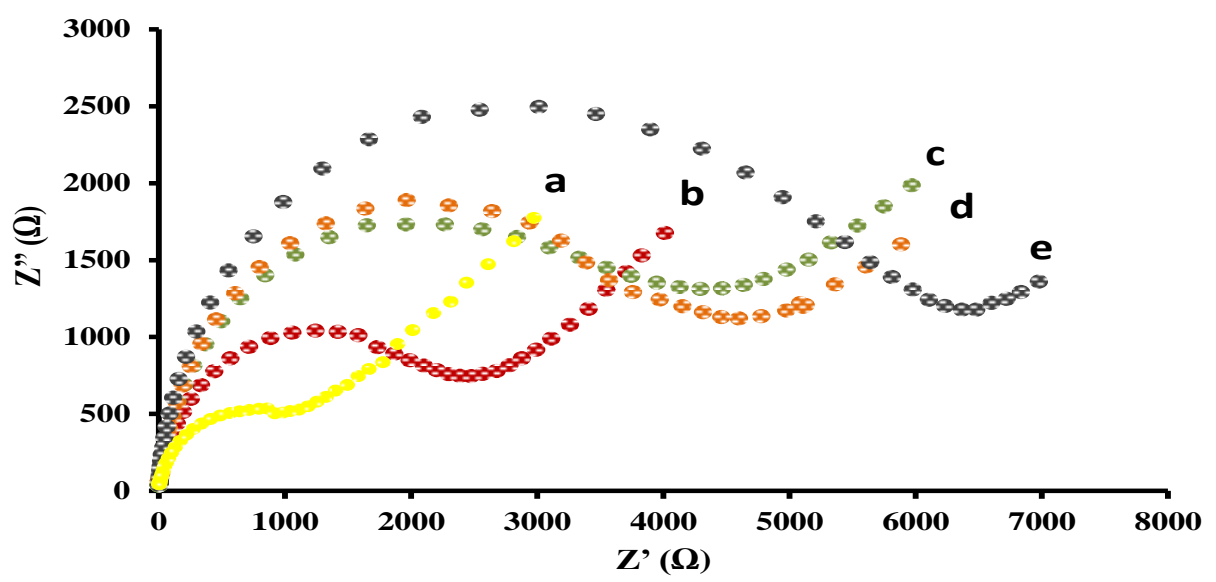

B

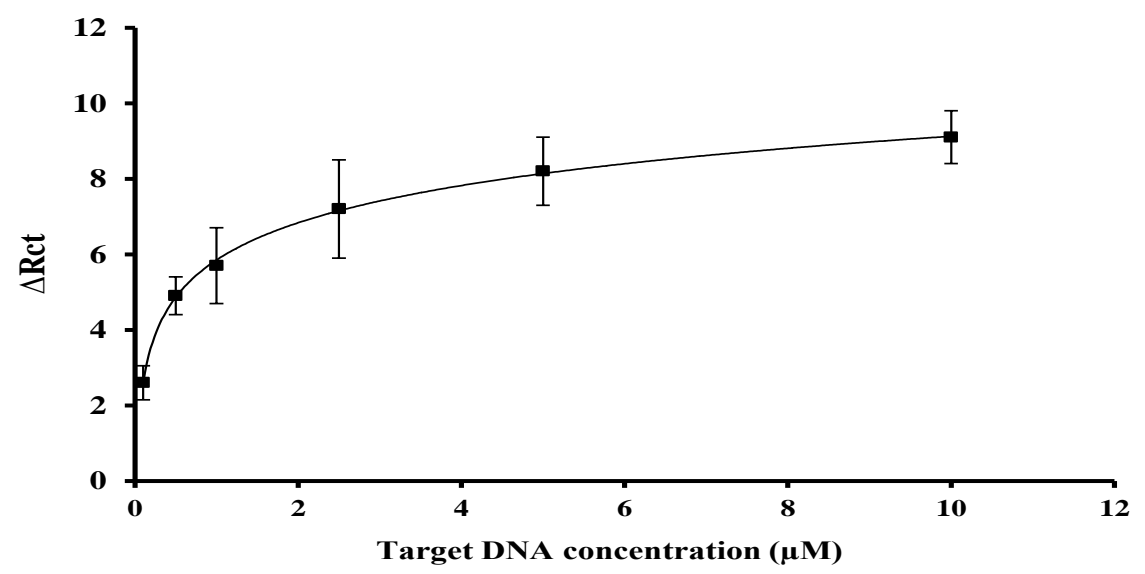

Figure 5. A) Nyquist plots recorded for control DNA a) and CTV-related ssDNA concentrations of $0.1 \mu \mathrm{M} \mathrm{b}), 0.5 \mu \mathrm{M}$ c), $1 \mu \mathrm{M}$ d) and $10 \mu \mathrm{M}$ e). Electrolyte: $0.5 \mathrm{mM}$ $\mathrm{K}_{3}\left[\mathrm{Fe}(\mathrm{CN})_{6}\right] / \mathrm{K}_{4}\left[\mathrm{Fe}(\mathrm{CN})_{6}\right]$ containing $0.1 \mathrm{M} \mathrm{KCl}$; Potential: $0.2 \mathrm{~V}$; Amplitude: $5 \mathrm{mV}$; Frequency range: $10 \mathrm{KHz}$ to $0.5 \mathrm{~Hz}$. B) Calibration curve obtained by plotting the normalized $\mathrm{R}_{\mathrm{ct}}$ values vs the logarithm of different CTV-related DNA concentrations in the range of 0.1 to $10 \mu \mathrm{M}$. Other experimental conditions as described in the text.

Additionally, interference studies were performed to examine the selectivity of our developed DNA sensor. Under optimized experiment conditions, the thiolated ssDNA-AuNP modified electrodes were covered with solutions of target DNA mixed with interferents (partially and fully non-complementary DNAs) at $1: 0 ; 1: 1 ; 1: 5$ and $1: 10$ ratios. Notably, the impedance results were significantly affected when the concentration of partially non-complementary DNA was 10 times the target DNA concentration (data not shown). To improve the sensor selectivity, probe DNA with spacer of poly (AT) was served to form the recognition layer. 
Additionally, mercaptohexanol $(\mathrm{MCH})$ was used as backfiller to minimize and effectively inhibit any non-specific adsorption of nucleobases, as reported in previous studies.

Gold nanoparticle surfaces were treated with poly (AT)-thiolated ssDNA probe in the presence of $\mathrm{MCH}$ (with DNA: $\mathrm{MCH}=1: 0.1$ ) for initial DNA immobilization process. Impedance measurements performed in target DNA solutions containing interfering of noncomplementary DNA sequences, suggesting better selective DNA interaction as no significant interferences were observed (Figure 6A).
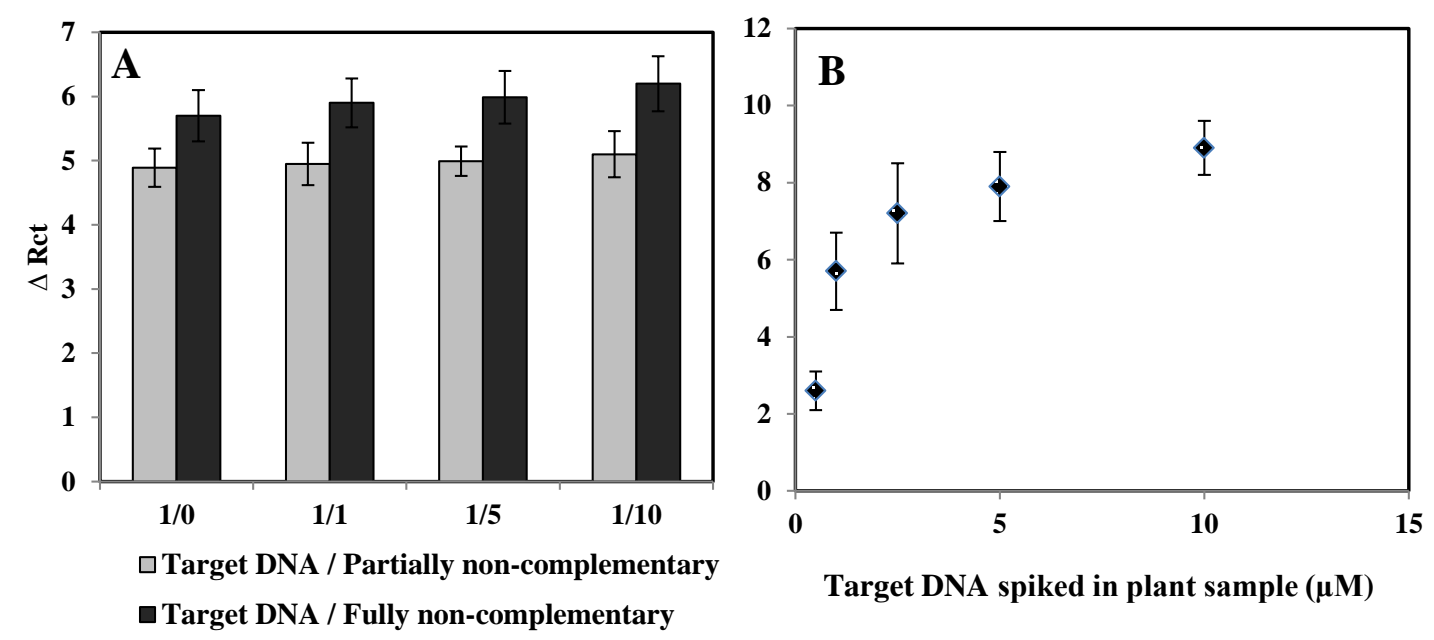

Figure 6. A) Interference study on the MCH/poly (AT) thiolated ssDNA-AuNPs modified electrodes towards a) target DNA/fully non-complementary and b) target DNA/ partially noncomplementary at different rations $(n=3)$ B) Effect of the concentration of CTV-related DNA (from of 0.5 to $10 \mu \mathrm{M}$ ) spiked in real plant samples on thenormalized $R_{c t}$ values .

The same system reported above was tested in leaf extracts from healthy citrus plants to assess its ability to quantify CTV nucleic acid in real biological samples. Leaf extracts were prepared in hybridization buffer and diluted 5 times and then spiked with five different target DNA concentrations $(0.5,1,2.5,5$ and $10 \mu \mathrm{M}) . \Delta$ Rct were recorded and the results proved enough sensor sensitivity to detect the target DNA concentration as low as $500 \mathrm{nM}$ (Figure 6B). Moreover, the biosensor ability to recover different target DNA concentrations from 
plant sample matrix was studied and the results demonstrated the satisfactory recovery within the range of $90-97 \%$ (Table 1).

\begin{tabular}{cccc}
\hline Spiked CTV $(\mu \mathrm{M})$ & $\begin{array}{c}\Delta \text { Rct in } \\
\text { hybridization buffer }\end{array}$ & $\begin{array}{c}\Delta \text { Rct in } \\
\text { plant sample }\end{array}$ & Recovery \% \\
\hline 0.5 & 2.6 & 1.65 & 95 \\
1 & 5.7 & 5 & 97 \\
2.5 & 7.1 & 6.16 & 94 \\
5 & 7.9 & 7 & 90 \\
10 & 8.9 & 7.98 & 92 \\
\hline
\end{tabular}

Table 1. Recovery study of the developed DNA biosensor in spiked plant samples with $(0.5$, $1,2.5,5$ and $10 \mu \mathrm{M})$ of synthetic CTV-DNA.

The reproducibility of responses for a $1 \mu \mathrm{M}$ of target ssDNA on the thiolated ssDNA-AuNP surfaces was also studied, obtaining a relative standard deviation (RSD) of $17 \%$ which demonstrated the good performance of this proof-of-concept approach. For further improvements so as to get better repeatability between the different electrodes, intra- and inter-day assays variability were performed on $\mathrm{MCH} /$ poly (AT) thiolated ssDNA-AuNPs sensing layer (Table 2). The intra-day assays were conducted on the same single day while the inter-day assays required one assay/day for 5 sequential days. The mean value, standard deviation and coefficient of variation were calculated using five different target DNA concentrations $(10,20,30,40$ and $50 \mu \mathrm{M})$. For these target DNA concentration, the mean coefficient of variation values of intra- and inter- day precision assays were $6.78 \%$ and 7.72 $\%$, both of which are less than $10 \%$ of RSD. These results indicate the good reproducibility performance of the proposed DNA sensor.

\begin{tabular}{cllllll}
\hline \multirow{2}{*}{$\begin{array}{c}\text { Target } \\
\text { Concentration }(\mu \mathrm{M})\end{array}$} & \multicolumn{3}{c}{ Intra-assay $(\mathrm{n}=4)$} & \multicolumn{3}{c}{ Inter-assay $(\mathrm{n}=4)$} \\
\cline { 2 - 8 } & \multicolumn{1}{c}{ SRct } & S.D & Coefficient of variation \% & $\Delta$ Rct & S.D & Coefficient of variation \% \\
\cline { 3 - 7 } 10 & 9.12 & 0.3 & 3.28 & 8.90 & 0.43 & 4.83 \\
20 & 10.33 & 0.5 & 4.84 & 10.56 & 0.59 & 5.58 \\
30 & 11.89 & 1 & 8.4 & 11.07 & 0.89 & 8.03 \\
40 & 12.57 & 1.3 & 10.34 & 12.88 & 1.26 & 9.78 \\
50 & 12.76 & 0.9 & 7.05 & 12.90 & 1.34 & 10.38 \\
\hline
\end{tabular}

Table 2. Intra- and inter-day reproducibility assays of the CTV-DNA sensor. 


\section{CONCLUSION}

We have developed the first DNA hybridization sensor based on AuNP- modified SPCE employing label-free impedance for the detection of CTV-related nucleic acid. AuNPs were electrochemically deposited on the working carbon electrode for its easy preparation and strong affinity with bio-recognition receptors with reactive groups (e.i. thiols) . Covalent attachment of thiolated ssDNA probe was obtained to form the sensing layer that recognizes target ssDNA. A simple rapid label-free impedance detection of CTV was developed on AuNP-modified electrodes and faradic impedance was used to investigate the electrochemical performance. Impedance was selected as the best parameter to monitor the interfacial charge transfer changes of the electrode surface resulting from duplex DNA formation. To evaluate the sensor performance corresponding to selectivity and reproducibility, interference studies along with intra- and inter-day assays were conducted. The use of $\mathrm{MCH}$ and poly AT thiolated DNA probe has enhanced the sensor selectivity when it was tested against partially and fully non-complementary DNA sequences. The results demonstrated that $2 \mathrm{~h}$ is needed to form the recognition layer (MCH/poly (AT) thiolated ssDNA probe) followed by detecting the target DNA through base pairing time no longer than $1 \mathrm{~h}$ and finally within 5 min a detectable stable electrochemical signal is generated and collected. Our DNA sensor showed a logarithm relation in the range of $0.1-10 \mu \mathrm{M}$ of CTV-related DNA with LOD of $100 \mathrm{nM}$ with a total assay time of 65 min (60 min DNA hybridization and 5 min readout). Moreover, the results demonstrated the good reproducibility of the biosensors with RSD less than $10 \%$. The developed DNA sensor exhibits great advantages over previously reported dot-blot hybridization approaches for CTV-nucleic acid based detection in terms of simplicity, time of analysis and ability to do quantitative analysis. The proposed biosensor is of high potential interest for in-field applications in the relevant field of plant pathogen detection, which would overcome the limitations of classical methods such as dot-blot hybridization. 


\section{ACKNOWLEDGMENTS}

The ICN2 is funded by the CERCA programme / Generalitat de Catalunya. The ICN2 is supported by the Severo Ochoa programme of the Spanish Ministry of Economy, Industry and Competitiveness (MINECO, grant no. SEV-2013-0295). Mohga Khater thanks Autonomous University of Barcelona for the opportunity of performing this work inside the framework of Biotechnology PhD Programme.

\section{REFERENCES}

Arduini, F., Micheli, L., Moscone, D., Palleschi, G., Piermarini, S., Ricci, F., Volpe, G. 2016. Trends Anal. Chem. 79, 114-126.

Bar-Joseph, M. 2015. J. Citrus Pathol. 2(1).

Bar-Joseph, M., Garnsey, S. M., Gonsalves, D., Moscovitz, M., Purcifull, D. E., Clark, M. F., Loebenstein, G. 1979. Phytopathol. 69, 190-194.

Bar-Joseph, M., Marcus, R., Lee, RF., 1989. Annu. Rev. Phytopathol. 27, 291-316.

Benvidi, A., Firouzabadi, A. D., Tezerjani, M. D., Moshtaghiun, S. M., Mazloum-Ardakani, M., Ansarin, A., 2015. J. Electron. Chem. 750, 57-64.

Bonanni, A., Esplandiu, M. J., Del Valle, M., 2008. Electrochim. Acta 53, 4022-4029.

Cash, K. J., Heeger, A. J., Plaxco, K. W., Xiao, Y., 2008. Anal. Chem. 81, 656-661.

Castañeda, M. E., Alegret, S., Merkoci, A. 2007. Electroanal. 19, 743-753.

Castañeda, M. T., Alegret, S., Merkoçi, A. 2009. Biosensors and Biodetection; Methods in Molecular Biology ${ }^{\mathrm{TM}}$, vol 504. Humana Press. 
Cui, M., Wang, Y., Wang, H., Wu, Y., Luo, X. 2017. Sens. Actuator B-Chem. 244, 742-749.

De la Escosura-Muñiz, A., Baptista Pires, L., Serrano, L., Altet, L., Francino, O., Sánchez, A., Merkoçi, A. 2016. Small, 12, 205-213.

De la Escosura-Muñiz, A., Mekoçi, A. 2010. Chem. Comm., 46, 9007-9009.

De la Escosura-Muñiz, A., Merkoçi, A. 2014. Nucleic Acid Nanotechnology, Springer, Berlin, Heidelberg, 305-332.

Deng, C., Chen, J., Nie, Z., Wang, M., Chu, X., Chen, X., Yao, S., 2008. Anal. Chem. 81, 739-745.

Fang, Y. and Ramasamy, R.P., 2015. Biosens. 5(3), 537-561.

Haji-Hashemi, H., Norouzi, P., Safarnejad, M. R., Ganjali, M. R. 2017. Sens. Actuator BChem. 244, 211-216.

Harper, S. J., \& Cowell, S. J. 2016. J. Citrus Pathol. 3(1).

Hassen, W. M., Chaix, C., Abdelghani, A., Bessueille, F., Leonard, D., Jaffrezic-Renault, N., 2008. Sen. Actuators B: Chem.134, 755-760.

Huang, Z., Rundell, P. A., Guan, X., Powell, C. A., 2004. Plant Dis. 88, 625-629.

Ito, T., Hosokawa, K., Maeda, M., 2007. Biosens. Bioelectron. 22, 1816-1819.

Karoonian, F. S., Etesami, M., and Mohamed, N. ,2012. chemija, 23(4).

Khater, M., de la Escosura-Muñiz, A., Merkoçi, A., 2017. Biosens. Bioelectron. 93, 72-86.

Korkmaz, S., Cevik, B., Onder, S., Koc, K., Bozan, O., 2008. N. Z. J. Crop. Horticul. Scienc. 36, 239-246.

Lai, R. Y., Weiwei, Y. A. N. G., 2011. U.S. Patent Application No. 12/967,547. 
Li, X., Shen, L., Zhang, D., Qi, H., Gao, Q., Ma, F., Zhang, C., 2008. Biosens. Bioelectron. 23, 1624-1630.

Licciardello, G., Scuderi, G., Ferraro, R., Giampetruzzi, A., Russo, M., Lombardo, A., Catara, A. 2015. Arch. Virol. 160, 2583-2589.

Liu, S. F., Li, Y. F., Li, J. R., Jiang, L., 2005. Biosens, Bioelectron. 21, 789-795.

Maheshwari, Y., Selvaraj, V., Hajeri, S., Ramadugu, C., Keremane, M. L., Yokomi, R. K. 2017. Phytoparasit. 45, 333-340.

Martinelli, F., Scalenghe, R., Davino, S., Panno, S., Scuderi, G., Ruisi, P., Villa, P., Stroppiana, D., Boschetti, M., Goulart, L.R., Davis, C.E., 2015. Agron. Sustaine. Dev. 35(1), $1-25$.

Mayorga-Martinez, C. C., Chamorro-García, A., Serrano, L., Rivas, L., Quesada-Gonzalez, D., Altet, L., Merkoçi, A.2015. J. Mater. Chem. B, 3, 5166-5171.

Mazloum-Ardakani, M., Rajabzadeh, N., Benvidi, A., Heidari, M. M., 2013. Anal. Biochem. 443, 132-138.

Merkoçi, A., Aldavert, M., Marın, S., Alegret, S. 2005. Trends in Anal. Chem. 24, 341-349.

Merkoçi, A., Biosens. Bioelectron. 2010, 26, 1164-1177.

Moreno, P., Ambrós, S., Albiach-Martí, MR., Guerr,i J., Peña, L., 2008. Mol. Plant Pathol. 9, $251-268$.

Nezhad, A.S., 2014. Lab Chip 14(16), 2887-2904.

Niblett, C. 2000. U.S. Patent No. 6,140,046. Washington, DC: U.S. Patent and Trademark Office.

Park, J. Y., Park, S. M., 2009. Sens., 9, 9513-9532. 
Peng, H. P., Hu, Y., Liu, P., Deng, Y. N., Wang, P., Chen, W., Lin, X. H. 2015. Sen. Actuators B: Chem. 207, 269-276.

Pereira, S. V., Bertolino, F. A., Fernández-Baldo, M. A., Messina, G. A., Salinas, E., Sanz, M. I., Raba, J. 2011. Analyst, 136, 4745-4751.

Pournaghi-Azar, M. H., Alipour, E., Zununi, S., Froohandeh, H., Hejazi, M. S., 2008. Biosens. Bioelectron. 24, 524-530.

Pumera, M., Castaneda, M. T., Pividori, M. I., Eritja, R., Merkoçi, A., Alegret, S. 2005. Langmuir, 21, 9625-9629.

Rasheed, P. A., Sandhyarani, N. 2017. Microchim. Acta. 184, 981-1000.

Rashid, J. I. A., Yusof, N. A., 2017. Sens. Bio-Sens. Res.

Ribovski, L., Zucolotto, V., Janegitz, B. C. 2017. Microchem. J. 133, 37-42.

Roberts, M.J., Schimmelpfennig, D.E., Ashley, E., Livingston, M.J., Ash, M.S., Vasavada, U., The Value of Plant Disease Early-Warning Systems: A Case Study of USDA's Soybean Rust Coordinated Framework; United States Department of Agriculture, Economic Research Service: Washington, DC, USA, 2006.

Savary, S., Ficke, A., Aubertot, J., Hollier, C. 2012. Food Secur. 4, 519-537.

Travas-Sejdic, J., Peng, H., Kilmaitin, P. A., Cannell, M. B., Bowmaker, G. A., Cooney, R. P., Soeller, C., 2005. Synth. Metals, 152, 37-40.

Voccia, D., Bettazzi, F., Fratini, E., Berti, D., \& Palchetti, I. 2016. Anal. Bioanal. Chem. 408, 7271-7281.

Wang, J., 2002. Anal. Chim. Acta, 469, 63-71.

Wang, J., Liu, G., Merkoçi, A. 2003a. J. Am. Chem. Soc., 125, 3214-3215. 
Wang, J., Liu, G., Merkoçi, A. 2003b. Anal. Chim. Acta, 482, 149-155.

Wang, J., Liu, G., Polsky, R., Merkoçi, A. 2002. Electrochem. Commun. 4, 722-726.

Wang, J., Polsky, R., Merkoci, A., Turner, K. L. 2003c. Langmuir, 19, 989-991.

Warghane, A., Misra, P., Bhose, S., Biswas, K. K., Sharma, A. K., Reddy, M. K., Ghosh, D. K. 2017. J. Virol. Method. 250, 6-10.

Wu, H., Zuo, Y., Cui, C., Yang, W., Ma, H., Wang, X., 2013. Sensors 13(7), 8551-8563.

Xu, Y., Cai, H., He, P. G., Fang, Y. Z., 2004. Electroanal. 16, 150-155.

Yokomi, R. K., Saponari, M., Sieburth, P. J., 2010. Phytopathol. 10, 319-327.

Zhang, K., Ma, H., Zhang, L., \& Zhang, Y., 2008. Electroanal. 20, 2127-2133.

Zhang, L., Li, Z., Zhou, X., Yang, G., Yang, J., Wang, H., Lu, Y., 2015. J. Electroanal. Chem.757, 203-209. 